\title{
Flash Electroretinogram Abnormalities in Patients with Clinically Definite Multiple Sclerosis
}

\author{
STUART G. COUPLAND and TREVOR H. KIRKHAM
}

SUMMARY: We studied the flash electroretinograms (ERGs) of 105 patients with multiple sclerosis who were divided into four groups. The first group had no history or clinical evidence of optic nerve dysfunction, the second and third groups had either left or right optic nerve disease respectively, and the fourth group had historical or clinical evidence of bilateral optic nerve disease.

Statistical analysis of the data using analysis of variance ( $A N O V A$ ) showed that the group of patients with no history or clinical evidence of optic nerve disease had no significant difference from the control group for their peak b-wave implicit times but the other three groups were significantly delayed on the affected side(s). Using the Mann-Whitney U-test we found all four

RESUMÉ: Une ètude a été réalisée sur des électrorétinogrammes (ERG) chez 105 patients souffrants de la sclerose en plaques. Il y avait quatre groupes de malades. Le premier ne démontrait aucune évidence de dysfonction du nerf optique, les deuxieme et troisieme groupes avaient été atteints du côté gauche ou du coté droit respectivement et le quatrième groupe démontrait une évidence de dysfonction bilatérale du nerf optique. Une étude statistique utilisant l'analyse de variance (ANOVA) nous montrait que les malades qui n'avaient aucune évidence de dysfonction du nerf optique ne démontraient aucune délai de l'onde " $b$ " de l'ERG en patient groups had significantly greater $a b$ solute interocular latency differences from the control group. The electroretinal contribution to flash VEP delay was also investigated. In those patients with unilateral or bilateral optic nerve disease we found that in $14-31 \%$ of those patients with flash $V E P$ delay there was also abnormal prolongation of the ERG b-wave. These results confirm a high incidence of retinal dysfunction in multiple sclerosis patients and may suggest that transynaptic degeneration of retinal structures occurs in optic nerve demyelination. The significant absolute interocular latency difference in particular may provide another electrophysiological parameter to establish a diagnosis of multiple sclerosis in suspect cases.

comparaison avec le groupe témoin. Pourtant, les malades avec une évidence de dysfonction du nerf optique avaient des différences significatives. Tout les quatre groupes avaient des différences significatives du groupe témoin du point de vue de la différence de latence interoculaire. Les résultats confirment que la dysfonction rétinienne dans la sclérose en plaques est fréquente. Il se peut qu'une dégénérescence trans-synaptique se produise quand il y a un épisode de démyélinisation du nerf optique. Les différences de la latence interoculaire peuvent être utiles afin de déceler la sclérose en plaques dans certains cas.
From the Departments of Neurology, Neurosurgery and Ophthalmology, McGill University, and the Department of Neuro-Ophthalmology at the Montreal Neurological Hospital.

Requests for reprints to: Dr. T.H. Kirkham, Department of Neuro-Ophthalmology, Montreal Neurological Hospital, 3801 University \#201, Montreal, Quebec, Canada H3A 2B4.

\section{INTRODUCTION}

Delays in the visual evoked potential (VEP) in multiple sclerosis (MS) populations are well recognized. It was initially thought that the visual evoked potential delay was a direct consequence only of conduction slowing in demyelinated visual pathways but recent investigations into the pathophysiology of multiple sclerosis suggest that other factors, including afferent volley dispersion and selective blocking of faster conducting fibers, might contribute to the observed VEP delay. Unrecognized humoral factors which affect synaptic transmission in MS and a possible retinal contribution to VEP delay might exist (McDonald, 1977).

Loss of the retinal nerve fibre layer in MS patients can be recognized clinically by using red-free light ophthalmoscopy (Frisen and Hoyt, 1974). This loss represents retrograde degeneration following demyelination of the axons of the ganglion cells of the retina. It must be recognized that this loss is not reflected by the flash electroretinogram (ERG) which measures only preganglionic retinal function, the b-wave component of which reflects current flow in the glial supporting Muller cells of the retina (Newman, 1980).

Electroretinographic evidence for retinal dysfunction in MS has not been investigated in any depth and the available data are somewhat inconsistent in terms of the specific waveform changes reported. Gills (1966) observed "low normal" or subnormal bwave amplitudes. Feinsod et al. (1973) detected supernormal, normal and subnormal b-waves while Paty et al. (1976) found enhanced a- and b-waves. However, other investigators have reported normal ERG waveforms in MS patients (Halliday et al., 1972; Babel et al., 1977; Ikeda et al., 1978). Several possibilities exist to explain these markedly discrepant ERG 
findings in MS patients. Different methods of stimulation and ERG recording might be important. The relatively small group sizes employed could increase variability in sample statistics. Further, the criteria used to establish the diagnosis of MS were not stated. For these reasons we decided to objectively quantify the flash ERG abnormalities which might be found in a large population of patients in whom the diagnosis of multiple sclerosis is firmly established.

\section{MATERIALS AND METHODS}

We examined 44 normal controls and 105 patients who had clinically definite MS as defined by the McDonald and Halliday (1977) criteria.

The patients were divided into four groups depending upon the presence or absence of a history of optic neuritis or of clinical features enabling a diagnosis of optic nerve disease to be made. The first group comprised 31 patients in whom there was no historical or clinical evidence for optic nerve disease and these we called "MS normal vision" (Table 1). The second and third groups were those patients who gave a positive history of an episode of acute unilateral optic neuritis involving the left $(\mathrm{N}=8)$ or right $(\mathrm{N}=12)$ eye and in whom there was clinical evidence of unilateral optic nerve disease (OND). These groups we called "MS left OND" and "MS right OND" respectively (see Table 1). The fourth group comprised 54 patients who either gave a history of episodes of bilateral optic neuritis and who had clinical evidence for bilateral optic nerve disease or who gave a history of unilateral OND but yet had clinical evidence of bilateral OND and this group we called "MS bilateral OND" in Table 1.

The clinical criteria used to establish the presence of optic nerve disease were subnormal corrected visual acuity, defective colour vision using the Ishihara test, presence of a relative afferent pupillary defect or an abnormality on kinetic Goldmann perimetry, abnormal prolongation of the pupil cycle time and recognisable optic atrophy (Kirkham and Coupland, 1981).

\footnotetext{
STIMULATION AND RECORDING METHODS

Electroretinograms (ERGs) were
}

recorded with $\mathrm{Ag}-\mathrm{AgCl}$ skin electrodes secured on the infraorbital ridge by hypoallergenic adhesive tape. These active sites were referenced to linked mastoids. Skin electrodes were used for recording the ERG since they do not interfere with the optics of the visual system and are comfortable for the patient, not requiring local anaesthesia to the eye and providing no risk of corneal abrasions as may be produced by cumbersome corneal contact lens electrode assemblies. Although the ERG amplitude from skin electrodes is much smaller than from contact lens electrodes, it is of the same order (5 15 microvolts) as the visual evoked potential which is well known to neurologists and is also recorded with surface electrodes. Using signalaveraging techniques the $b$-wave peak latency is readily identifable and the waveforms are in good correspondence with the ERG recorded with corneal contact lens electrodes as has been shown in several laboratories (Tepas and Armington, 1962; Berry, 1976; Gutrow-Tyler, Crews and Drasdo, 1978; Coupland, 1978). Visual evoked potentials (VEPs) were recorded from $\mathrm{O}_{1}$ and $\mathrm{O}_{2}$ referenced to linked mastoids.

Since the retina rapidly light adapts to flicker stimulation only a short dark adaptation period of 3 minutes was used. After the dark adaptation period the patient binocularly viewed a circular flickering test field. Flicker stimulation was produced by a Grass PS-22 Photostimulator (Grass Instruments, Quincy, Mass.) set at inten-

TABLE 1

ANOVA Summary Table of Flash E.R.G. Results

\begin{tabular}{|c|c|c|c|c|c|}
\hline \multirow[b]{3}{*}{$\begin{array}{l}\text { Normal Controls } \\
(N=44)\end{array}$} & \multicolumn{3}{|c|}{$\begin{array}{l}\text { b-wave implicit time } \\
\text { (mean } \pm \text { s.d.) }\end{array}$} & \multicolumn{2}{|c|}{$\begin{array}{c}\text { Interocular Latency } \\
\text { Difference } \\
\text { L }-\mathbf{R}\end{array}$} \\
\hline & Left Eye & $\mathbf{F}$ & Right Eye & $\mathbf{F}$ & (mean $\pm \mathrm{sd}$ ) \\
\hline & $65.3 \pm 7.9$ & & $66.4 \pm 7.0$ & & $-1.0 \pm 3.9$ \\
\hline $\begin{array}{l}\text { M.S. Norm. Vis. } \\
(\mathrm{N}=31)\end{array}$ & $69.2 \pm 14.0$ & $2.36 \&$ & $69.5 \pm 12.0$ & $2.05 \&$ & $-0.3 \pm 7.5$ \\
\hline $\begin{array}{l}\text { M.S. Left OND } \\
(\mathrm{N}=8)\end{array}$ & $74.7 \pm 11.9$ & $8.15+$ & $69.8 \pm 11.4$ & $1.38 \&$ & $+4.9 \pm 5.7$ \\
\hline $\begin{array}{l}\text { M.S. Right OND } \\
(N=12)\end{array}$ & $68.0 \pm 7.5$ & $1.09 \&$ & $71.8 \pm 6.3$ & $5.98^{*}$ & $-3.8 \pm 7.2$ \\
\hline $\begin{array}{l}\text { M.S. Bilat. OND } \\
(N=54)\end{array}$ & $69.2 \pm 11.5$ & $3.51 \#$ & $71.5 \pm 12.4$ & $6.00^{*}$ & $-2.4 \pm 9.1$ \\
\hline
\end{tabular}

sity $=16$ and projecting through a Wratten 47B filter masked to provide a 6.5 degree field flickering at $4 \mathrm{~Hz}$. Slow flicker has proved more effective than single-flash transient stimulation for eliciting ERG responses with less myogenic contamination since eyeblinks are not stimulus-locked to $4 \mathrm{~Hz}$. flicker. It has been our experience that the test field size and dominant wavelength chosen produce the most reliable flicker ERG waveforms which are easily scored. Test-field luminance was $250 \mathrm{~cd} / \mathrm{m}^{2}$ when flickering at $50 \mathrm{~Hz}$ as determined by a Hagner S-2 Universal Spot Photometer (Optikon Corp., Waterloo, Ont.).

The raw ERG and EEG signals were amplified 50,000X by Grass P511-J preamplifiers with a $0.1-300 \mathrm{~Hz}$ bandwidth and 128 samples were signal averaged using an LSI-11 microprocessor-based TN-1710 multichannel analyser (Tracor-Northern Ltd., Wisc.) and the averaged waveforms were stored on floppy disk. The ERG and VEP waveforms were visually inspected by an experienced technician who was kept experimentally naive. The ERG b-wave peak implicit time (the time from stimulus onset to the peak of the b-wave) and peak latency of the first negative (N70) and major positive peak (P110) of the binocular flash VEP were determined within each set of records. Implicit time and peak latency values were defined as "delayed" if they exceeded $99 \%$ of the normal control group values.

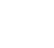




\begin{tabular}{|c|c|c|c|}
\hline & Left E.R.G. & Right E.R.G. & Left - Right \\
\hline Normals & 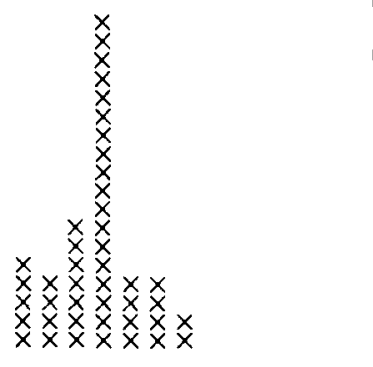 & 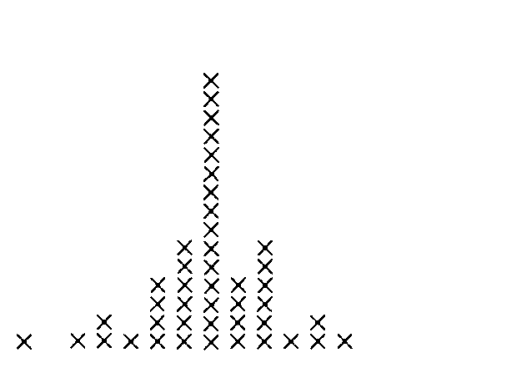 & 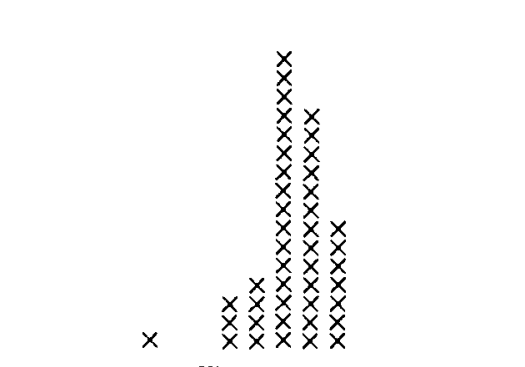 \\
\hline Left O.N.D. & $\stackrel{x}{x} \times \stackrel{x}{x} \times x \quad x$ & $\stackrel{\stackrel{x}{x}}{x} \quad x \quad \stackrel{x}{x} \quad x \quad x$ & $x \underset{x}{\stackrel{x}{x}} \underset{x}{x}$ \\
\hline Right O.N.D. & $\begin{array}{r}x \\
x \\
x \\
x \\
x \quad x \\
\times \quad x \quad x \times\end{array}$ & 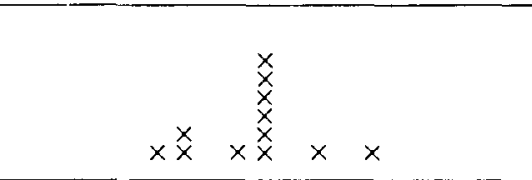 & $\begin{array}{l}x \\
x \\
x \\
x \\
x \\
x \\
x \\
x \\
x\end{array}$ \\
\hline Bilateral O.N.D. & 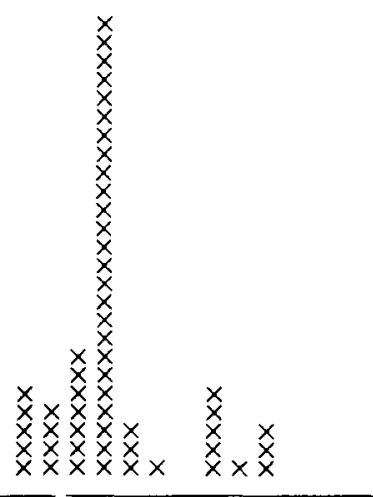 & 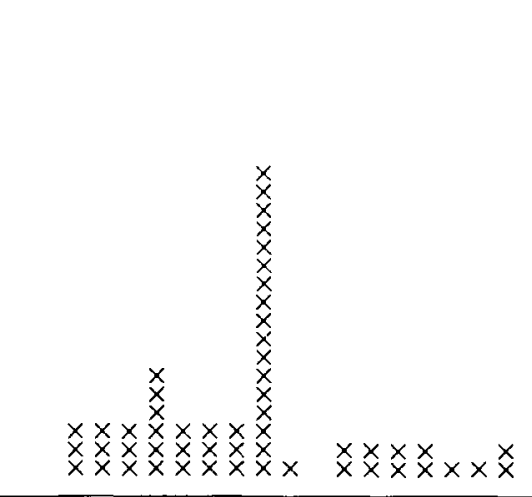 & 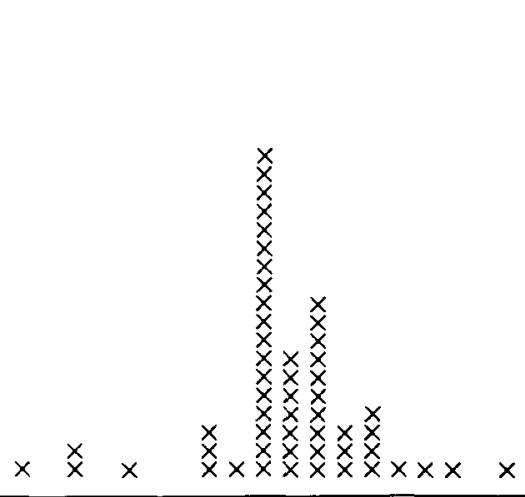 \\
\hline M.S. "Normals" & 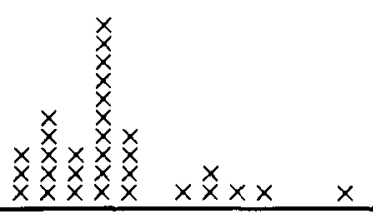 & 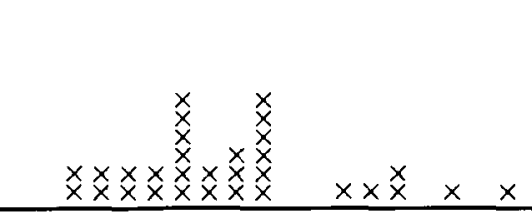 & 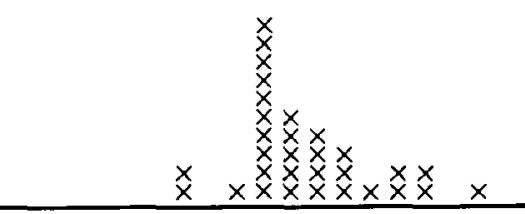 \\
\hline Msec. & 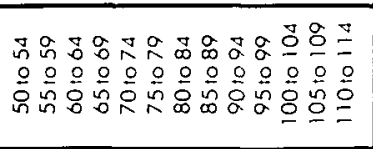 & 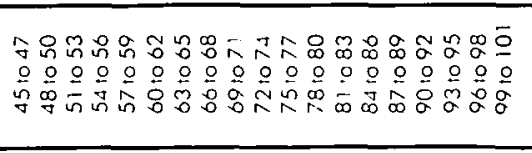 & 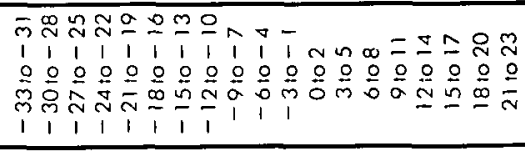 \\
\hline
\end{tabular}

Figure 1 - Frequency histograms of b-wave implicit times for the normal control and MS groups to monocular stimulation of the right and left eye. Those MS patients with normal vision are referred to as MS "Normals". The interocular latency difference (left minus right) distributions appear on the far right.

\section{RESULTS}

Mean flash ERG b-wave implicit times and standard deviations for the normal control group and the four MS groups were summarized in Table 1. The mean b-wave implicit times of all four MS groups are greater than the normal controls; in addition, latency variability is much greater in the MS groups.

Frequency histograms for the right and left ERG b-wave implicit time and interocular (left minus right) difference are presented in Figure 1. The "MS normal vision" group have a latency distribution that has greater variability than the normal control group frequency distribution of latencies. For the affected eye in both unilateral optic nerve disease groups, the $b$-wave latency distribution is shifted rightward toward higher latency values (Table 1 and Figures 2,3). The bilateral OND group latency distributions from both eyes are also similarly shifted (Table 1 and Figure 4). The interocular latency frequency distributions reveal obvious skewing for the left and right OND groups (Figure 1).

Since the interocular latency difference frequency distributions are skewed (Figure 1), the overall L - R difference scores were tested using a nonparametric Kruskal-Wallis (Siegel, 1956) one-way analysis of variance to determine whether the 5 independent samples are from the same or different populations. The overall KruskalWallis statistic was significant (for 


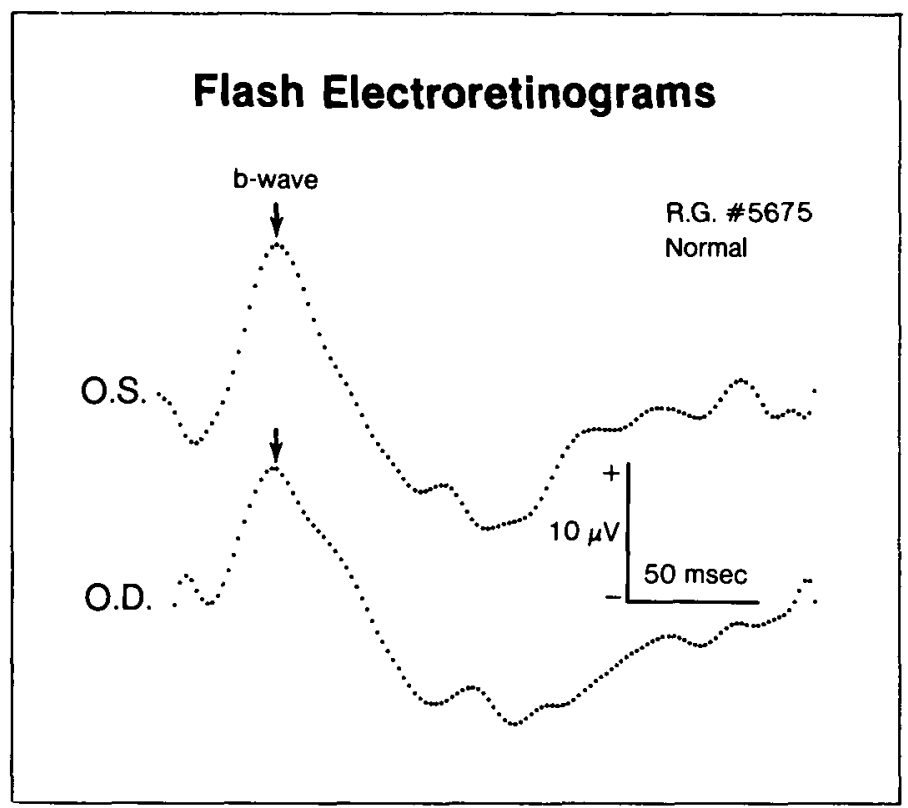

Figure 2 - Flash ERG waveforms from a normal control subject. Peak bwave implicit time is measured from the beginning of the tracing to the arrow marker.

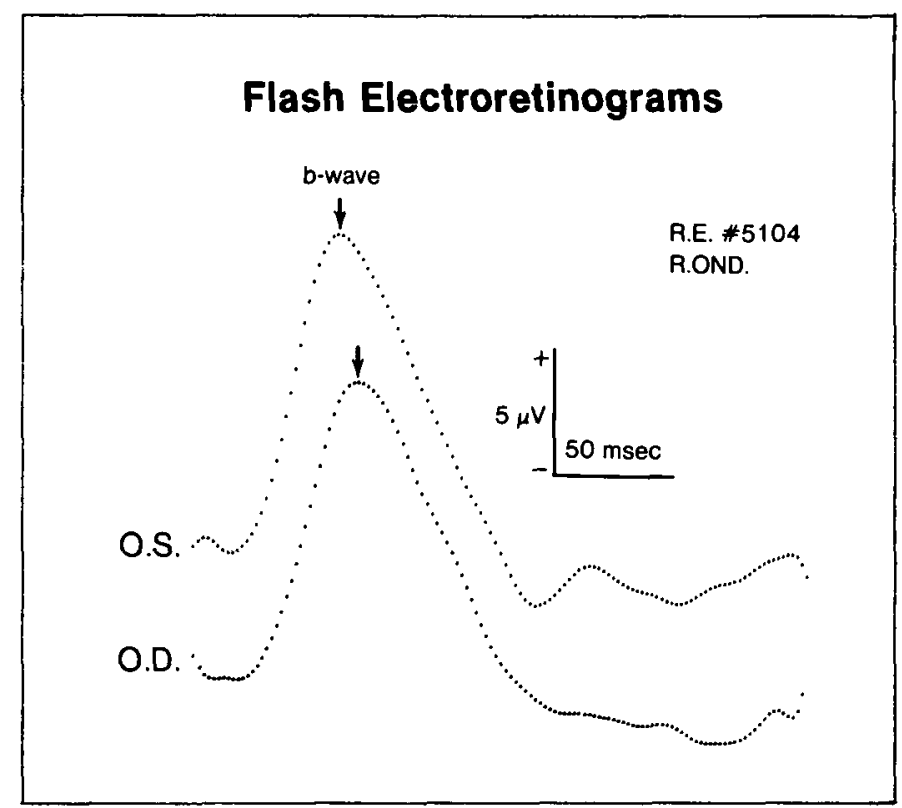

Figure 3 - Flash ERG waveforms in a case of unilateral optic nerve disease showing the obvious delay in the b-wave implicit time on the affected side. $\mathrm{df}=4, \mathrm{H}=14 \mathrm{p}<.01$ ) indicating that the differences among our samples reflect genuine population differences.

One-way analysis of variance (ANOVA) was used to compare each of the four MS group mean implicit times with the normal control group values. Those MS patients with no history or clinical evidence of optic nerve disease had no significant difference in the mean b-wave implicit time when compared to controls for either the left $(F=2.36$ n.s. $)$ or the right $(F=2.05$ n.s.) eyes. For those MS patients with clinical evidence of left optic nerve disease the $b$-wave implicit times from the affected side were significantly delayed $(F=8.15 p<.01)$ while those from the unaffected side were not $(F=1.38$ n.s. $)$. Similarly for those MS patients with right optic nerve disease the flash ERG b-waves were significantly delayed on the affected side $(F=5.98 p<.05)$ and nondelayed on the unaffected side $(F=1.09$ n.s.). The group of MS patients with a history or clinical evidence of bilateral optic nerve involvement had b-waves which were significantly delayed for both the left $(F=3.51 \mathrm{p}<.07)$ and right $(F=6.00 p<.05)$ eyes.

The absolute interocular latency difference score (Table 2) is a more appropriate measure of interocular dysfunction especially for the "MS normal vision" and bilateral OND groups whose $\mathrm{L}-\mathrm{R}$ scores are just as likely to be positive as negative. A MannWhitney $U$ test was used to compare absolute interocular latency difference scores between the four MS groups and the normal control group. The MannWhitney $U$ test results are summarized in Table 2 and indicate that all four MS groups have significantly greater ab- solute interocular latency differences than the normal control group.

The relationship between ERG and flash VEP delay is summarized in Table 3 for all MS patient groups. The right and left OND groups were combined to form a larger sample size of patients with unilateral OND $(\mathrm{N}=20)$. Only $20-25 \%$ of those patients with unilateral or bilateral OND were found to be electrophysiologically normal on

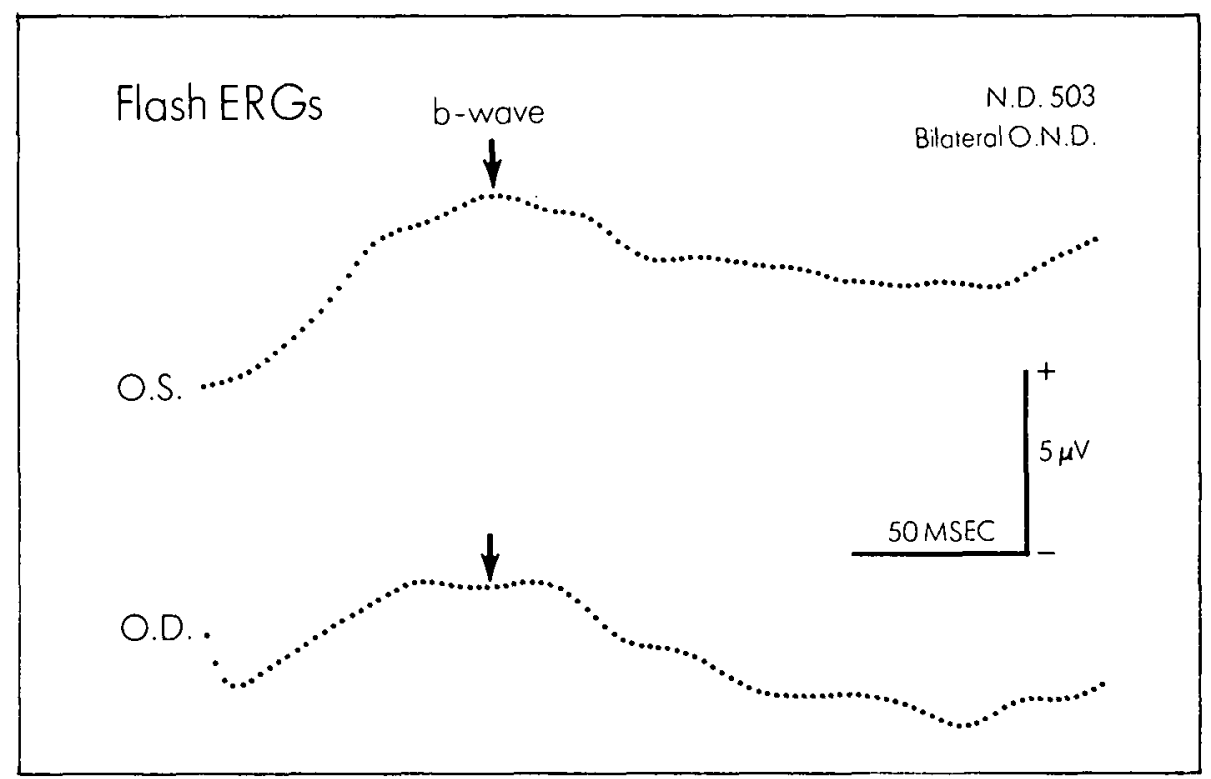

Figure 4 - Flash ERG waveforms in a case of bilateral optic nerve disease showing a greatly reduced amplitude and broadening of the b-wave with bilaterally increased b-wave implicit time. 
our flash stimulation measures. In the $75-80 \%$ of those MS patients with unilateral or bilateral OND there was evidence of VEP delay. In the unilatera! OND group, prolonged $b$-wave implicit times were present in $14 \%$ of patients with VEP delay. ERG b-wave delay was found in $31 \%$ of those patients in the bilateral OND group with VEP delay.

\section{DISCUSSION}

The present study of the ERG in MS patients was undertaken because of the inconsistent reports in the literature concerning ERG abnormalities in MS. Electroretinal function, determined by the flash ERG in optic nerve demyelination, has been reported to be of normal amplitude and latency from the affected and unaffected eyes of patients with unilateral optic neuritis (Halliday et al., 1972; Babel et al., 1977). However, Gills (1966) studied 27 patients with MS and found that 23 of them showed a reduction of some of the flash ERG components exceeding 2 standard deviations from his normal control group. He considered that the ERG amplitude reduction paralleled to some extent the degree of severity of the clinical manifestations of the disease and also reflected the severity of visual dyfunction. He considered that the earliest evidence of retinal dysfunction in MS subjects could be detected using light adapted red stimuli or by using $20 \mathrm{~Hz}$. flickering stimuli. Ikeda et al. (1978) did not observe any ERG abnormalities in a group of 28 patients diagnosed as having MS using flicker or flash stimuli, again using a response amplitude criterion. Interestingly, using flicker stimulation of $20 \mathrm{~Hz}$. the ERG amplitude for their normal group had a mean around 150 microvolts while that

TABLE 2

Flash E.R.G. Interocular Implicit time difference

\begin{tabular}{lrr}
\hline \multicolumn{1}{c}{$\begin{array}{c}\text { Absolute } \\
\text { Interocular Difference } \\
\text { (mean } \pm \text { s.d.) }\end{array}$} & Mann-Whitney U \\
Normal Controls & $2.4 \pm 3.1$ & \\
M.S. Norm. Vis. & $5.7 \pm 4.7$ & $350(\mathrm{p}<.01)$ \\
M.S. Left OND & $5.9 \pm 4.5$ & $89(\mathrm{p}<.05)$ \\
M.S. Right OND & $6.3 \pm 4.9$ & $110(\mathrm{p}<.01)$ \\
M.S. Bilat. OND & $6.5 \pm 7.2$ & $714(\mathrm{p}<.01)$ \\
\hline
\end{tabular}

of Gills' (1966) control group was only around 65 microvolts. Feinsod et al. (1973) studied 35 patients and reported that one-third of their cases had supernormal, one-third normal, and onethird subnormal $\mathbf{b}$-wave amplitudes. They categorized their patients into those with current visual dysfunction, those with a previous history of optic neuritis and those who had no historical or clinical evidence of optic nerve disease. They claimed to have found the same range of ERG amplitude in all 3 groups but they did not state normal mean and standard deviation values. They postulated that optic nerve demyelination might interrupt some centrifugal inhibitory fibres to the retina to explain their supernormal responses but no such fibres have been described in the optic nerve of man. Paty et al. (1977) reported supernormal ERGs in some patients with optic atrophy but did not quote normative data.

These inconsistencies from various laboratories which used similar techniques and our own experience, which has shown great variation in amplitude in our normal control group, has led us to the conclusion that amplitude is not a useful or reliable criterion for distinction between the normal and the diseased state. In contrast we find that peak latency of the b-wave is a constant and reliable indicator of normality and that in normals the interocular bwave latency difference is small (Tables 1 and 2).

Table 1 shows that the mean b-wave latencies of all the MS groups are higher than that of the normal control group and, with the exception of the right OND group, their standard deviations are also much greater than the normative group. The difference in the standard deviation size between the right OND and the left OND groups may in part be explained by the small number of subjects in these groups. Analysis of variance (ANOVA) showed that both unilateral OND group means were significantly delayed compared with the normal control group. In contrast the group of MS patients with no historical or clinical evidence of optic nerve dysfunction had no significant difference in b-wave implicit time from the normal control group as might have been expected. In addition, the group of MS patients with bilateral OND were significantly delayed in mean b-wave implicit times from both eyes.

What was also expected was the significant interocular latency differences between the normal eye and the affected eye in the left and right OND groups (Table 2). However, the bilateral OND group interocular latency difference was also significantly greater than the normals, suggesting the flash ERG is more sensitive in detecting asymmetrical involvement of the anterior visual system than are present clinical measures. Perhaps the most significant finding was that our group of MS patients who had no historical or clinical evidence of optic nerve disease $(\mathrm{N}=31)$ were also significantly different from our normal control group in so far as absolute interocular latency difference was concerned (Table 2) and these interocular differences are clearly seen in the frequency histograms in Figure 1. This provides further evidence that the $a b$ solute interocular latency difference is a sensitive measure of retinal dysfunction.

TABLE 3

Relationship between Flash ERG and VEP deficits in MS population

\begin{tabular}{lccc} 
& $\begin{array}{c}\text { Flash } \\
\text { ERG and VEP } \\
\text { normal }\end{array}$ & $\begin{array}{c}\text { Flash } \\
\text { VEP } \\
\text { delayed }\end{array}$ & $\begin{array}{c}\text { Proportion } \\
\text { of VEP delay } \\
\text { cases with } \\
\text { ERG delay }\end{array}$ \\
MS Normal Vision $(\mathrm{N}=31)$ & $8(26 \%)$ & $21(68 \%)$ & $1 / 21(4 \%)$ \\
* Unilateral OND $(\mathrm{N}=20)$ & $5(25 \%)$ & $15(75 \%)$ & $2 / 15(14 \%)$ \\
Bilateral OND $(\mathrm{N}=54)$ & $11(20 \%)$ & $43(80 \%)$ & $13 / 43(31 \%)$ \\
\hline
\end{tabular}

* Unilateral OND group = Right OND + Left OND 
The electroretinal contribution to flash VEP delay is summarized in Table 3. In those patients with VEP delay there was evidence of abnormal prolongation in $\mathbf{b}$-wave implicit time in $31 \%$ of the bilateral OND group, in $14 \%$ of the unilateral OND group, and in only $4 \%$ of those MS patients with clinically normal vision. Generally, we observed that our patients who had bilateral OND had more clinically demonstrable visual signs of optic nerve involvement and have greater neurological impairment than the patients with a history of unilateral visual loss or with clinically normal vision. We interpret these results as suggesting that the frequency of electroretinai dysfunction seen in our patients could reflect the slowly progressive degeneration of the nerve fiber layer with subsequent retrograde transynaptic degeneration to the inner nuclear layer possibly affecting the supportive glial cells which are responsible for propagation of the electroretinal bwave (Newman, 1980).

Thus we have found evidence of significantly prolonged b-wave implicit times in MS patients who have clinical or historical evidence of previous optic nerve disease in one or both eyes. Furthermore, even in MS patients who have no evidence of optic nerve dysfunction clinically or by history we have found delayed ERGs and a significant group difference in absolute interocular implicit time. It was not the intention of the present paper to claim that recording the ERG could have the same diagnostic value as the VEP in the diagnosis of MS since Table 3 clearly indicates the relative frequency of ERG delay is always less than the frequency of observed VEP delay. The ERG signals recorded by our technique have the same amplitude as the visual evoked potentials and are readily identifiable and are as easily recorded as the VEP. Thus the ERG may provide an additional method for aiding the clinician to make the diagnosis of MS by electrophysiological studies in patients who do not have visual symptoms or in those patients who do not have delayed visual evoked potentials. Using flash visual evoked potentials we were able to confidently find between
$68-80 \%$ of our MS patients had demonstrable electrophysiological abnormalities. Interestingly, in this group of 105 patients reported here with clinically definite MS, pattern reversal VEPs have been recorded to two pattern orientations and we found abnormally delayed responses in $60-71 \%$ of cases dependent upon pattern orientation (Coupland and Kirkham, 1982).

The important conclusion for this paper based upon our empirical findings is that there are abnormalities in the distal unmyelinated structures of the retina in patients with definite MS whether or not they have suffered overt optic nerve demyelination detectable clinically or by pattern visual evoked potentials. The cause of these flash ERG abnormalities in MS patients remains unknown. Possibly retrograde transynaptic degeneration of the distal unmyelinated structures of the retina may occur when there is optic nerve damage. Presently, we are continuing our investigation of electroretinal and visual evoked potential abnormalities using both flash and pattern stimulation to determine the relationship between peripheral and central visual system involvement in MS.

\section{ACKNOWLEDGEMENTS}

Dr. S.G. Coupland is a Post Doctoral Fellow supported by the Multiple Sclerosis Society of Canada. The work was aided by a grant from the Canadian National Institute for the Blind out of the E.A. Baker Foundation. The Town of Mount Royal Old Timers Executive Hockey League, The Kiwanis Club of Royal Mount and The St. Nicholas and St. George Men's Clubs, Montreal provided assistance towards the establishment of our visual neurophysiology laboratory. We thank Dr. J.B.R. Cosgrove, Dr. Y. Lapierre, Dr. W. Barkas and Dr. J. Rubin for referring their patients for study. Dr. D. Bishop provided valuable statistical consultation. Judy Bengle, R.N. gave competent technical assistance.

\section{REFERENCES}

BABEL, J., STANGOS, N., KOROL, S. and SPIRITUS, M. (1977) Ocular electrophysiology: a clinical and experimental study of electroretinogram. Publ. George Thiem, Stuttgardt.
BERRY, H. (1976) Clinical electroretinography by the skin electrode and signal averaged method. Can. J. Ophthalmol. 11: 160-164.

COUPLAND, S.G. (1978) Time-domain analysis of steady-state electroretinal and visual evoked response to intermittent photic stimulation. Ph.D. thesis. Simon Fraser University.

COUPLAND, S.G. and KIRKHAM, T.H (1982) Orientation-specific visual evoked potential deficits in multiple sclerosis. Can. J. Neurol. Sci. 9: 331-337.

FEINSOD, M., ABRAMSKY, O. and AUERBACH, E. (1973) Electrophysiological examination of the visual system in multiple sclerosis. J. Neurol. Sci. 20: 161-175.

FRISEN, L. and HOYT, W.F. (1974) Insidious atrophy of retinal nerve fibers in multiple sclerosis. Arch. Ophthalmol. 82: 91-97.

GILLS, J.P. (1966) The electroretinogram after section of the optic nerve in man. Am. J. Ophthalmol. 62: 287-291.

GUTROW-TYLER, J.F., CREWS, S.J. and DRASDO, N. (1978) Electroretinography with noncorneal and corneal electrodes. Invest. Ophthalmol. Vis. Sci. 17: 1124-1127.

HALLIDAY, A.M., McDONALD, W.I. and MUSHIN, J. (1972) Delayed visual evoked response in optic neuritis. Lancet 1: 982 985.

IKEDA, H., TREMAIN, K.E. and SANDERS, M.D. (1978) Neurophysiological investigation in optic nerve disease: combined assessment of the visual evoked response and electroretinogram. Br. J. Ophthalmol. 62: 227-239.

KIRKHAM, T.H. and COUPLAND, S.G. (1981) Multiple regression analysis of diagnostic predictors in optic nerve disease. Can. J. Neurol. Sci. 8: 67-72.

McDONALD, W.I. (1977) Pathophysiology of conduction in central nerve fibers. From: Visual Evoked Potentials in Man-New Developments. Desmedt JD (ed), Clarendon Press, pp. 427-437.

MCDONALD, W.I. and HALLIDAY, A.M. (1977) Diagnosis and classification of multiple sclerosis. Br. Med. Bull., 33: 4-9.

NEWMAN, E.A. (1980) Current sourcedensity analysis of the b-wave of frog retina. J. Neurophysiol. 43: 1355-1366.

PATY, J., BRENOT, Ph., HENRY, P. and FAURE, J.M.A. (1976) Potentiels évoqués visuels et sclérose en plaques. Rev. Neurol. (Paris) 132: 605-621.

SIEGEL, S. (1956) Nonparametric statistics for the behavioral sciences. McGraw-Hill Publishers, New York.

TEPAS, D.I. and ARMINGTON, J.C. (1962) Electroretinograms from non corneal electrodes. Invest. Ophthalmol. 1 : 784-786. 